\title{
VLPC Characterization for the DZero Upgrade
}

D. Adams, M. Adams, B. Baumbaugh, I. Bertram, A. Bross, D. Casey, S. Chang, M. Chung, C. Cooper, C. Cretsinger, R. Demina, G. Fanourakis, T. Ferbel, S. Grunendahl, J. Hinson, B. Howell, H. Johari, J.S. Kang, C.L. Kim, S.K. Kim, D. Koltick, F. Lobkowicz, S. Margulies, J. Moromisato, M. Narain, C.H. Park, S. Reucroft, Y.M. Park, R. Ruchti, J. Solomon, E. VonGoeler, J. Warchol, M. Wayne, E. Won, Y. Yu

Representing the $\mathrm{D} \emptyset$ Collaboration

Fermi National Accelerator Laboratory, University of Illinois at Chicago, Korea University, Kyungsung University, Northeastern University, University of Notre Dame, Purdue University, Rice University, University of Rochester, Seoul National University

September 1994

Presented at the Eighth Meeting of the Division of Particles and Fields of the American Physical Society (DPF'94), Albuquerque, New Mexico, August 1-8, 1994 


\section{Disclaimer}

This report was prepared as an account of work sponsored by an agency of the United States Government. Neither the United States Government nor any agency thereof, nor any of their employees, makes any warranty, express or implied, or assumes any legal liability or responsibility for the accuracy, completeness, or usefulness of any information, apparatus, product, or process disclosed, or represents that its use would not infringe privately owned rights. Reference herein to any specific commercial product, process, or service by trade name, trademark, manufacturer, or otherwise, does not necessarily constitute or imply its endorsement, recommendation, or favoring by the United States Government or any agency thereof. The views and opinions of authors expressed herein do not necessarily state or reflect those of the United States Government or any agency thereof. 


\title{
VLPC CHARACTERIZATION FOR THE DZERO UPGRADE
}

D. Adams, M. Adams, B. Baumbaugh, I. Bertram, A. Bross, D. Casey, S. Chang, M. Chung, C. Cooper, C. Cretsinger, R. Demina, G. Fanourakis, T. Ferbel, S. Grünendahl, J. Hinson, B. Howell, H. Johari, J. S. Kang, C. L. Kim, S. K. Kim, D. Koltick, F. Lobkowicz, S. Margulies, J. Moromisato, M. Narain, C. H. Park*, S. Reucroft, Y. M. Park, R. Ruchti, J. Solomon, E. VonGoeler, J. Warchol, M. Wayne, E. Won, Y. Yu Fermi National Accelerator Laboratory, University of Ilinois at Chicago, Korea University, Kyungsung University, Northeastern University, University of Notre Dame, Purdue University, Rice University, University of Rochester, Seoul National University

\begin{abstract}
We have studied the performance characteristics of approximately 4000 Visible Light Photon Counters(VLPC) over a range of operating temperatures and biases. We will describe the characterization procedure and present the measured gain, noise, and relative quantum efficiency for the devices. We will also discuss the general operation of the devices and the significant problems encountered during the characterization.
\end{abstract}

\section{Introduction}

In $1997, \mathrm{D} \emptyset$ will upgrade the central tracking region of the detector with an entirely new system consisting of a 2 Tesla superconducting solenoid, a 6000 channel preshower detector made of scintillator with wavelength shifting fiber readout, an outer 80000 channel scintillating fiber tracker and an inner $10^{6}$ channel silicon strip tracker. ${ }^{1}$ The optical signal from the fibers will be detected by Visible Light Photon Counters(VLPCs). VLPCs are arsenic doped silicon diodes that operate near a temperature of $6.5 \mathrm{~K}$ with a bias of approximately $6.5 \mathrm{~V} .{ }^{2}$ The detailed examination of the characteristics of the VLPCs is the subject of this report.

\section{Characterization Stand}

\subsection{Characterization Procedure}

The VLPC chips are produced by Rockwell and are supplied as $1 \times 8$ pixel arrays with individual pixels of $1 \mathrm{~mm}$ diameter. The arrays are mounted on a ceramic substrate to form a hybrid and this hybrid is then mounted on a Torlon carrier that allows for fiber alignment with the pixels. Noise, gain, and quantum efficiency (QE) measurements were taken on all pixels at operating points between 5.5 and $7.0 \mathrm{~K}$

\footnotetext{
*Representing the D0 Collaboration.
} 


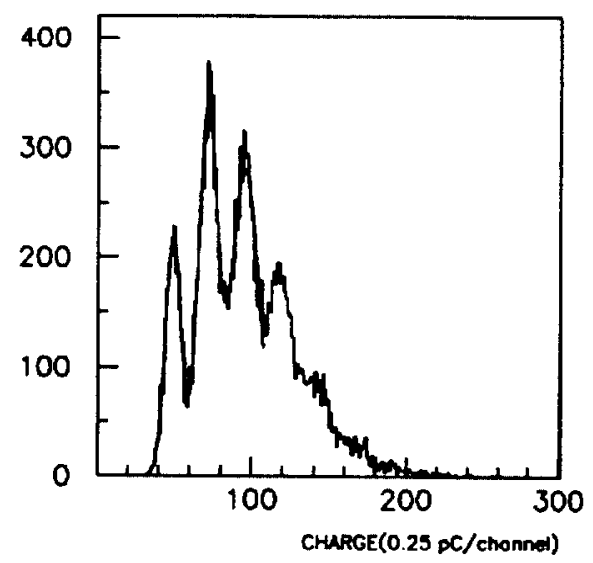

Fig. 1. A typical spectrum from a good VLPC pixel at $T=6.5 \mathrm{~K}$ and $\mathrm{V}=6.5 \mathrm{~V}$.

and with VLPC bias between 5.9 and $7.1 \mathrm{~V}$. An LED light pulser was used to inject an optical signal into the devices. Pulser data along with pedestal data were used to calculate noise, gain, and relative $\mathrm{QE}$.

\subsection{Systematic Errors}

The combined systematic errors on the gain due to the run to run change of cassette condition, the channel to channel variation of preamp gain and the channel to channel VLPC bias variation is about $5 \%$.

The channel to channel light level variation is estimated by cycling a hybrid (calibration chip) through each of the positions in the cassette and measuring the response. The systematic error on $\mathrm{QE}$ measurement from light level variation is about $5 \%$.

\section{Results}

Figure 1 shows a typical spectra obtained from a good pixel. One sees well separated pedestal, first and second photoelectron peaks.

\subsection{Dark Current}

Dark current was measured by fitting the pedestal spectra to a Gaussian distribution. The extra counts above the tail were considered to be dark current from single photoelectron events. The rates shown in Fig. 2 are essentially the singles rates at a threshold of 0.5 photoelectrons. 

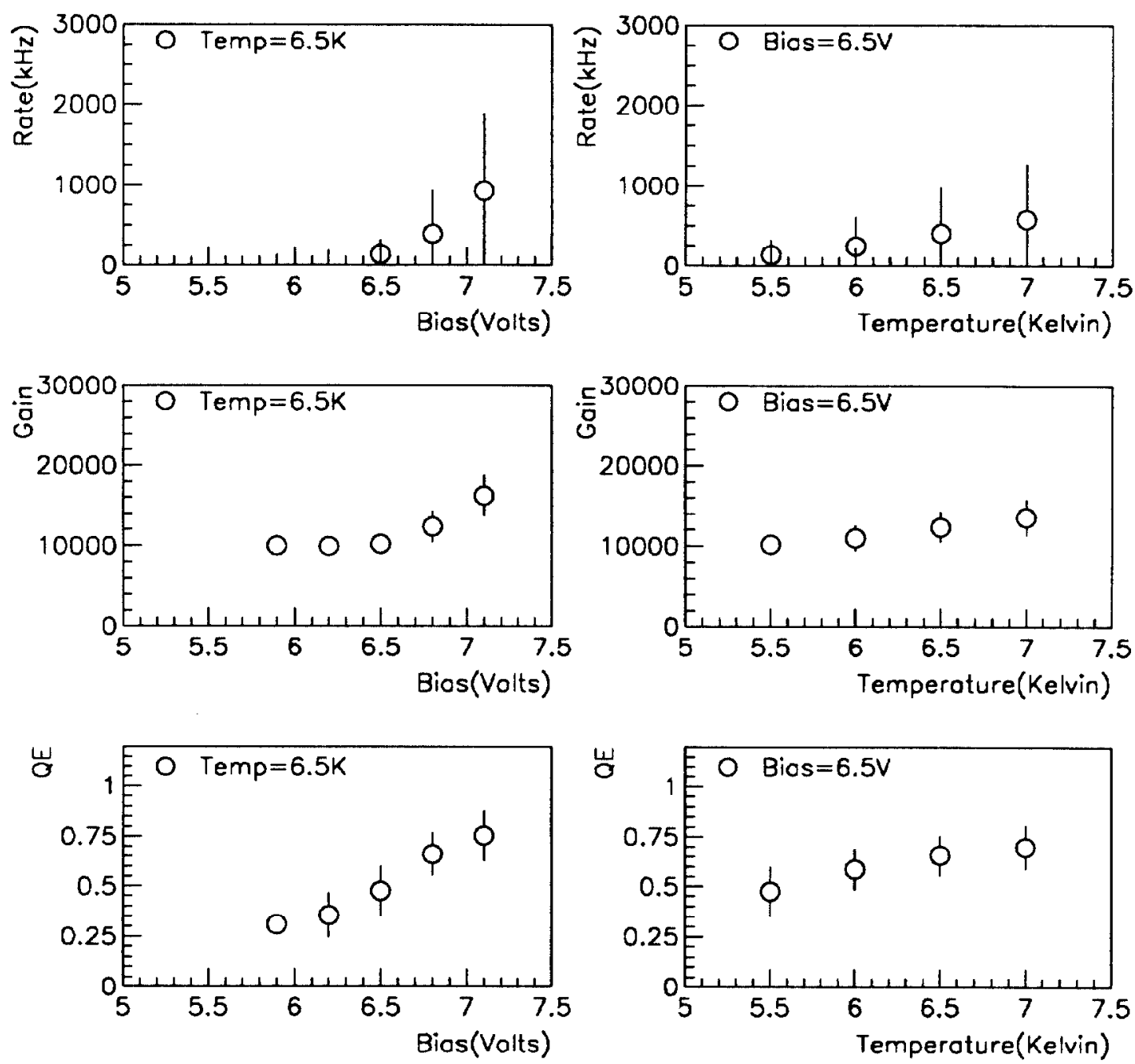

Fig. 2. Dark current, Gain and $Q E$ as a function of VLPC bias at $T=6.5 \mathrm{~K}$ and as a function of operating temperature at $\mathrm{V}=6.5 \mathrm{~V}$. 


\subsection{Gain}

The gain is defined as the difference between the first and second photoelectron peak positions. At our nominal operating point of $6.5 \mathrm{~V}$ and $6.5 \mathrm{~K}$, the gain $=12.6 \times$ $10^{4} \pm 2500$.

\subsection{Quantum Efficiency}

The relative $Q E$ is obtained by comparing the average number of photoelectrons observed from pixel to pixel and normalizing the distribution to an average QE of $60 \%$ at $6.5 \mathrm{~K}$ and $6.5 \mathrm{~V}$.

\subsection{Yield}

520 hybrids have been characterized. Of those characterized, 320 were considered good at the test stand by looking at spectra from the $T=6.5 \mathrm{~K}$ and $\mathrm{V}=6.5 \mathrm{~V}$ point, 120 had at least 1 bad pixel, and 80 were considered marginal and were retested. Of the marginal chips re-tested, 34 were recovered as good chips. The recovery can be attributed to better contact with the read-out springs in the cassette.

\section{Acknowledgements}

This research is being performed with the generous support of the Department of Energy.

\section{References}

1. E823 ( $D \emptyset$ Upgrade):DØ, $\mathrm{D} \emptyset$ note 1733 (1993)

2. M. D. Petrov, M. G. Stapelbroek, and W. Z. Kleinhans, Appl. Phys. Lett. 51, 406 (1987). 